\title{
Immunohistochemical Identification of GM-CSF in Testis of Rats with Oligozoospermia with the Intervention of Cuscuta chinensis Flavonoids
}

\author{
Identificación Inmunohistoquímica de GM-CSF en Testículos de Ratas con \\ Oligozoospermia con la Intervención de Flavonoides de Cuscuta chinensis
}

Meng Xiaotong; Liao Libin; Ma Yixuan; Aikebaier Kadier \& Bai Shengbin

XIAOTONG, M.; LIBIN, L.; YIXUAN, M.; KADIER, A. \& SHENGBIN, B. Immunohistochemical identification of GM-CSF in testis of rats with oligozoospermia with the intervention of cuscuta chinensis flavonoids. Int. J. Morphol., 38(3):761-765, 2020.

SUMMARY: Oligozoospermia is a common infertility disease, and the incidence rate is increasing year by year. Cuscuta chinensis is a commonly used medicine for the treatment of oligozoospermia in Chinese medicine. Flavonoids are its main component. GM-CSF is a multifunctional cytokine that plays an important role in the inflammatory response. In this paper, we performed HE staining and immunohistochemical staining on the testis of rats with oligozoospermia. We intend to study the expression changes of GM-CSF in rats with oligospermia and the effect of flavonoids on the expression of GM-CSF in testis of rats with oligozoospermia.

KEY WORDS: Cuscuta Chinensis Flavonoids; Oligozoospermia; GM-CSF.

\section{INTRODUCTION}

In recent years, more and more infertility patients have become global and social problems affecting human health and development, and are closely related to biological factors, environmental factors and social factors. Among these couples who have difficulty in having children, oligozoospermia accounts for a large proportion of male infertility and is increasing year by year.

There are many causes of oligozoospermia, such as infection, chromosomal abnormalities, gene deletion, environmental pollution, endocrine disorders, and career exposures may all lead to oligozoospermia. Many scholars are studying the etiology and pathogenesis of oligozoospermia. Although great achievements have been made, there is no clear answer so far, and there is no clear and effective method for the clinical treatment of oligozoospermia. In the days when we are striving to make breakthroughs in research, Chinese medicine is also advancing in exploration. Traditional Chinese medicine is commonly used Cuscuta chinensis to treat oligozoospermia.Studies have found that flavonoids are the main component of Cuscuta, which has attracted the attention of many scholars.
GM-CSF is a member of the type I cytokine receptor superfamily (Zhang et al., 2008). It not only plays a huge role in the hematopoietic system, but also is an effector with broad immunological activity in the body. GM-CSF can stimulate bone marrow hematopoietic stem cells to develop into monocytes or granulocytes, and can also regulate inflammation and immune response, so it is regarded as a sensitive marker of the body's inflammatory response (Lin $\& \mathrm{Wu}, 2019)$. Studies have shown that the GM-CSF content in seminal plasma of infertile men is significantly higher than that of men with normal fertility. We reasonably suspect that GM-CSF may be associated with the development of oligozoospermia.

Therefore, we intend to intervene in rats with cyclophosphamide, resulting in a rat model of oligozoospermia Sun et al., 2013; Ghobadi et al., 2017; Shabanian et al., 2017; Zeng et al., 2018; Potnuri et al., 2018. Next, we will further study the expression changes of testis GM-CSF in rats with oligozoospermia. We also used Cuscuta chinensis flavonoids to treat rats with oligozoospermia and explore the effect of flavonoids on the expression of GMCSF in testis. 


\section{MATERIAL AND METHOD}

Thirty male Sprague-Dawley rats weighing 250-300 $\mathrm{g}$ were purchased from the Animal Experimental Center of Xinjiang Medical University and kept in the SPF clean-grade animal room. The experimental animals were randomly divided into three groups: blank control group, model group and Cuscuta flavonoid group, with ten in each group. Throughout the experiment, normal feed and drinking water were provided and rats were given free access to water. After five days of adaptive feeding, modeling began. Rats in the model group and the flavonoids group were injected intraperitoneally with cyclophosphamide at a dose of $30 \mathrm{mg} /$ $\mathrm{kg}$ for 5 days to establish a model of oligozoospermia. At the same time, rats in the blank control group were intraperitoneally injected with an equal dose of normal saline. From the 6th day, the suspension of flavonoids was added (0.25 $\mathrm{g}$ of CMC-Na and $50 \mathrm{~mL}$ of pure water per gram of flavonoids), and the rats of the flavonoids group were perfused with flavonoids at a dose of $5 \mathrm{~mL} / \mathrm{kg}$ per day. For the suspension, rats in the model group and the blank control group were given an equal dose of normal saline for four consecutive weeks. Weighed weekly to adjust the dose administered.

After the last administration, the rats were weighed. 24 hours later, the rats were anesthetized with a concentration of $5.0-7.5 \mathrm{ml} / \mathrm{kg}$ by intraperitoneal injection of urethane at a concentration of $20 \%$. The bilateral testis and left epididymal tail were quickly removed from the rat. Weigh and calculate the testicular index. Testicular index $=$ sum of bilateral testicular mass / body weight $\times 100 \%$. The epididymis tail was placed in $2 \mathrm{ml}$ of pre-warmed M199 at $37^{\circ} \mathrm{C}$, cut with an ophthalmic scissors, and placed at $37^{\circ} \mathrm{C}$ for 15 minutes at a constant temperature to allow the sperm to fully swim out. $50 \mathrm{ml}$ was dropped on the hemocytometer plate, and the number of sperm and the activity rate were quickly observed under a microscope. The testes were fixed with 4 $\%$ paraformaldehyde. After 3 days, the testicles were cut along the long axis, and the fixing solution was replaced and fixed for 4 days. Dehydration was carried out with 75 $\%, 85 \%, 90 \%, 95 \%$ and $100 \%$ alcohol respectively, and then removed with xylene, embedded in paraffin, and cut into $5 \mathrm{~mm}$ thick slices and spread on glass slides.
The prepared sections should be placed in a $60{ }^{\circ} \mathrm{C}$ incubator for $1 \mathrm{~h}$. After dewaxing and rehydration, they were divided into two batches, one for HE staining and the other for immunohistochemistry. HE staining requires sequential hematoxylin staining for $8 \mathrm{~min}$, hydrochloric acid alcohol differentiation for $2 \mathrm{~s}$, tap water return to blue for $5 \mathrm{~min}$, eosin staining for $2 \mathrm{~min}$, and dehydration sealing. After completion, the morphological structure of the testis can be observed under light microscope. Immunohistochemistry requires incubation of $\mathrm{H}_{2} \mathrm{O}_{2}$ for $10 \mathrm{~min}$ at room temperature to block endogenous peroxidase interference, $15 \mathrm{~min}$ antigen repairing in sodium citrate $\mathrm{pH}$ 7.2-7.4 at $95{ }^{\circ} \mathrm{C}$, and serum blocking for $30 \mathrm{~min}$ at room temperature. Incubate the primary antibody overnight at $4{ }^{\circ} \mathrm{C}$. The second antibody was incubated for $30 \mathrm{~min}$ at room temperature the next day. DAB coloring solution was added dropwise, followed by hematoxylin staining for $4 \mathrm{~min}$, hydrochloric acid alcohol differentiation for $2 \mathrm{~s}$, tap water returning to blue for $3 \mathrm{~min}$, and dehydration sealing. After completion, the expression of GM-CSF in testis tissue was observed under light microscope.

\section{RESULTS}

Testicular index. After 4 weeks of administration, the body weight of the model group rats was lower than that of the blank control group and the dodder flavonoid group, but it was not statistically significant. There were no significant differences in rat body weight, testicular mass and testicular index between the groups (Table I).

Number of sperm and activity rate. The number and activity rate of sperm were counted under the light microscope using the hemocytometer. The sperm count and activity rate of the model group were lower than those of the flavonoid group and the blank control group $(\mathrm{P}<0.01)$. After the intervention of the flavonoids, the rats were treated. The sperm count and activity rate basically returned to normal levels, and the difference was not statistically significant with the blank control group (Table II).

Table I. Testicular index of rats after 4 weeks of administration.

\begin{tabular}{lccccc}
\hline \multirow{2}{*}{ Group } & \multicolumn{2}{c}{ Dosage } & Weight $/ \mathrm{g}$ & Testicular Weight/g & Testicular Index $/ \%$ \\
& Cyclophosphamide & $\begin{array}{c}\text { Flavonoid } \\
\text { Suspension }\end{array}$ & & & \\
\hline Blank Control Group & - & - & $320.08 \pm 48.07$ & $3.04 \pm 0.24$ & $0.87 \pm 0.08$ \\
Cuscuta Flavonoid Group & $30 \mathrm{mg} / \mathrm{kg}$ & $5 \mathrm{~mL} / \mathrm{kg}$ & $348.32 \pm 160.49$ & $2.63 \pm 0.63$ & $0.85 \pm 0.27$ \\
Model Group & $30 \mathrm{mg} / \mathrm{kg}$ & - & $304.17 \pm 49.39$ & $2.86 \pm 0.62$ & $0.94 \pm 0.13$ \\
\hline
\end{tabular}


Table II. Number of sperm and activity rate in each group of rats. 1) $\mathrm{P}<0.01$ compared with the model group; 2) $\mathrm{P}<0.01$ compared with the blank control group.

\begin{tabular}{lcc}
\hline Group & Sperm Density /_106·ml-1 & Sperm Activity Rate / \% \\
\hline Blank Control Group & $91.41 \pm 16.05$ & $56 \pm 15$ \\
Cuscuta Flavonoid Group & $100.05 \pm 24.78^{1_{-}}$ & $66 \pm 14^{1_{-}}$ \\
Model Group & $39.60 \pm 14.09^{2-}$ & $13 \pm 42_{-}$ \\
\hline Note: 1 ) Compared with the model group, P $<0.01 ; 2$ ) Compared with the blank control group, P \\
$<0.01$.
\end{tabular}

Testicular morphology. Under the light microscope, HE staining results showed that the testis tissue structure was intact in the blank control group, the basement membrane of the seminiferous tubule was continuous, and the interstitial cells (Leydig cells) were clearly visible. The thickness of the spermatogenic cells in each layer was moderate and neatly arranged, and the number of sperm cells was abundant. A large amount of sperm can be seen inside. Significant morphological changes were observed in the testicular tissue of the model group. The seminiferous tubules were deformed or even collapsed, the spermatogenic epithelium became thinner, the basement membrane was discontinuous, the Leydig cells were disordered. The spermatogenic cells are loosely arranged and have few sperm. In the flavonoids of Cuscuta chinensis, the small tubules were closely connected and the basement membrane was continuous. The thickness of spermatogenic cells in each layer was still thicker than that in the model group, and the number of primary spermatocytes was less than that in the blank control group (Figs. 1 and 2).

Immunohistochemistry results. Under the light microscope, the nuclei of the blank control group and the flavonoid group of the Cuscuta chinensis were stained blue-purple by hematoxylin, the background was clean, the boundary was
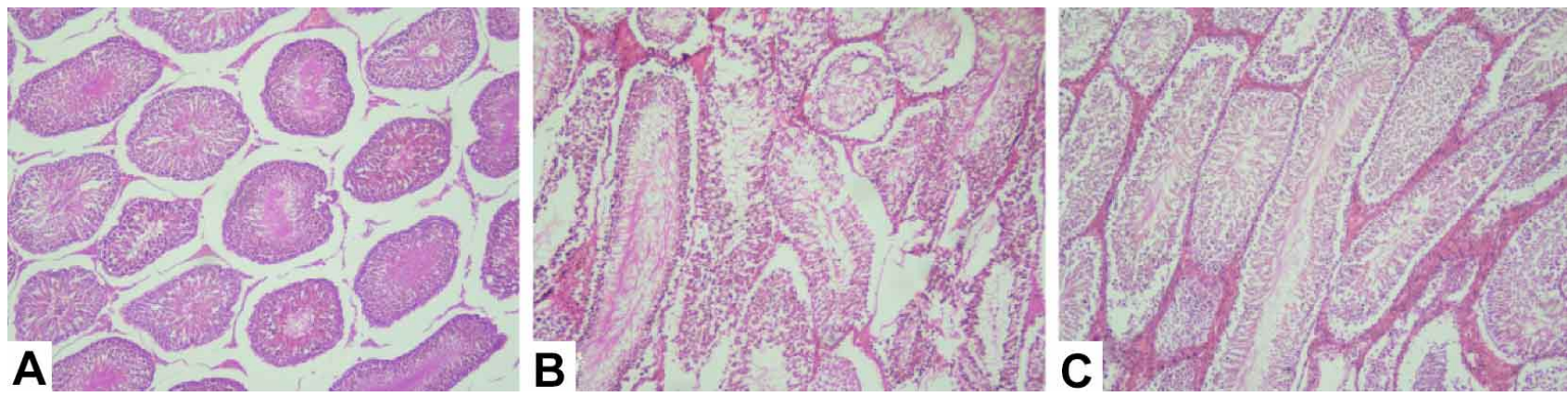

Fig. 1. This picture is seen under the light microscope. A is a blank control group. The histological structure of the seminiferous tubules is normal, the spermatogenesis is normal, and the seminiferous tubules have clear lumens and neatly arranged spermatogenic cells. interstitial cells are clearly visible. B is a model group. Significant morphological changes were observed in the testicular tissue, and the seminiferous tubules were deformed or even collapsed, the basement membrane was discontinuous, and the interstitial cells were disorderly arranged. $\mathrm{C}$ is a group of flavonoids. The testicular tissue structure is intact, the basement membrane of the seminiferous tubule is continuous, and the interstitial cells are clearly visible.H\&E; $\times 100$.
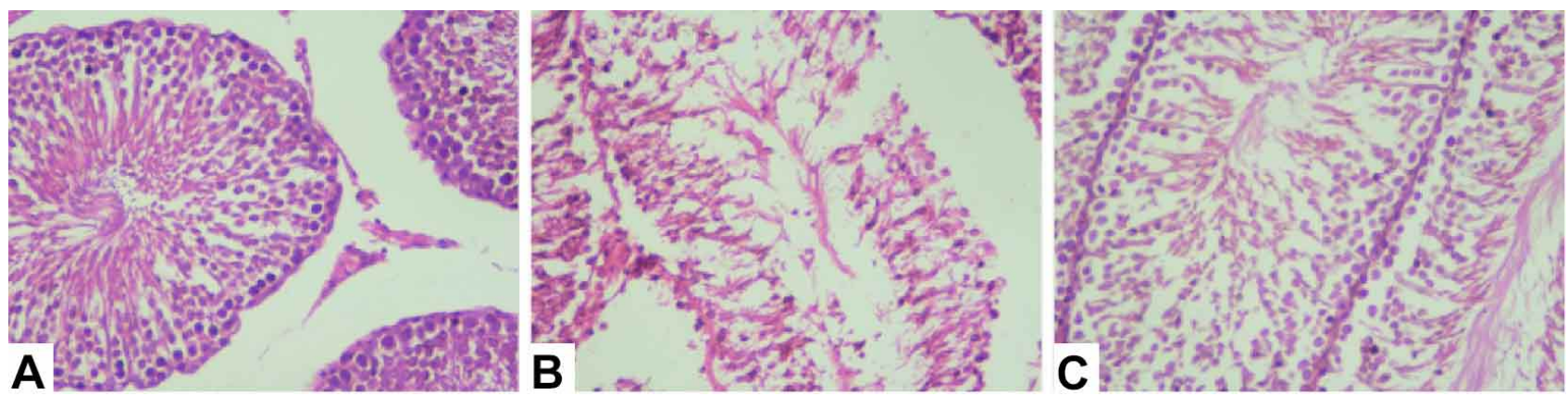

Fig. 2. This picture is seen under the light microscope. A is a blank control group. The spermatogenic cells of each layer are moderately thick and neatly arranged, and the number of sperm cells is abundant, and a large number of sperm are visible in the lumen. B is a model group. The epithelial cells of the seminiferous tubules become thinner, the interstitial cells of the testes are disorderly arranged, the spermatogenic cells are arranged loosely, the number is small, and the sperm cells in the lumen are sparse. C is a flavonoid group of dodder. The thickness of spermatogenic cells in each layer is still thicker than that of the model group. The number of primary spermatocytes is less than that of the blank control group, and there are a certain number of sperm cells in the official cavity $(\mathrm{H} \& \mathrm{E} ; \times 400)$. 
clear, no brownish yellow areas or particulate matter were observed, and no GM-CSF was expressed. In contrast, the model group showed obvious positive color development, and after amplification, there was a brown-yellow reaction in the cytoplasm, which was a positive expression signal of GM-CSF. As shown in Figures 3 and 4.
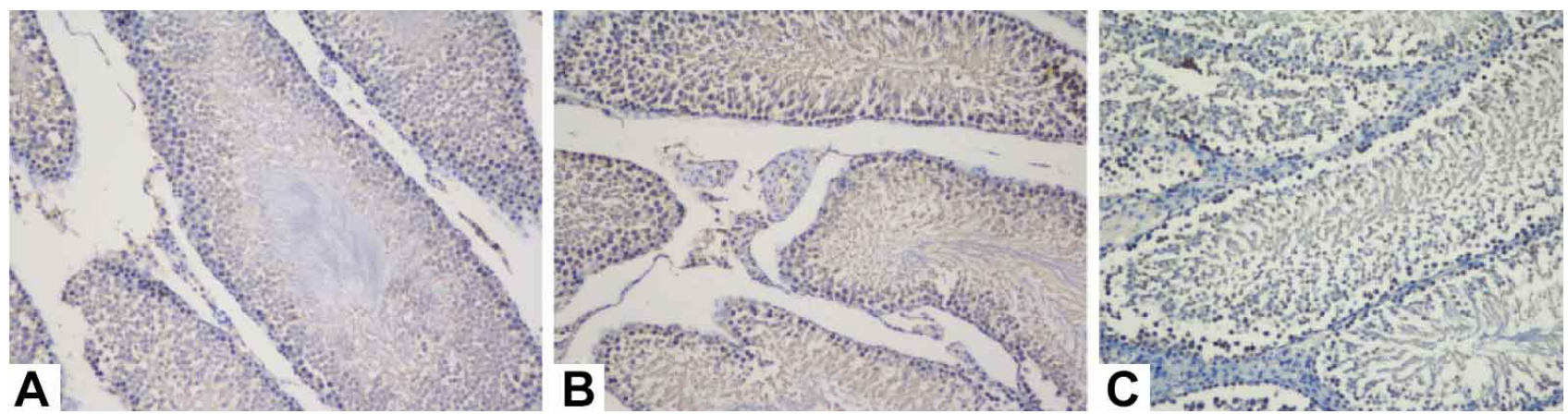

Fig. 3. A is a blank control group. The staining was clear, the background was clean, the nuclei were well stained blue-violet, and no brownish-yellow areas were seen. B is a model group. The color was significantly different from the blank control group. The nuclei of spermatogenic cells and mesenchymal cells were stained blue-violet, and the cytoplasm of some cells showed a brownish yellow color. $\mathrm{C}$ is a flavonoid group of dodder. Except for the blue-violet nuclei, no other obvious staining sites were seen. (H \& E; $\times 200)$
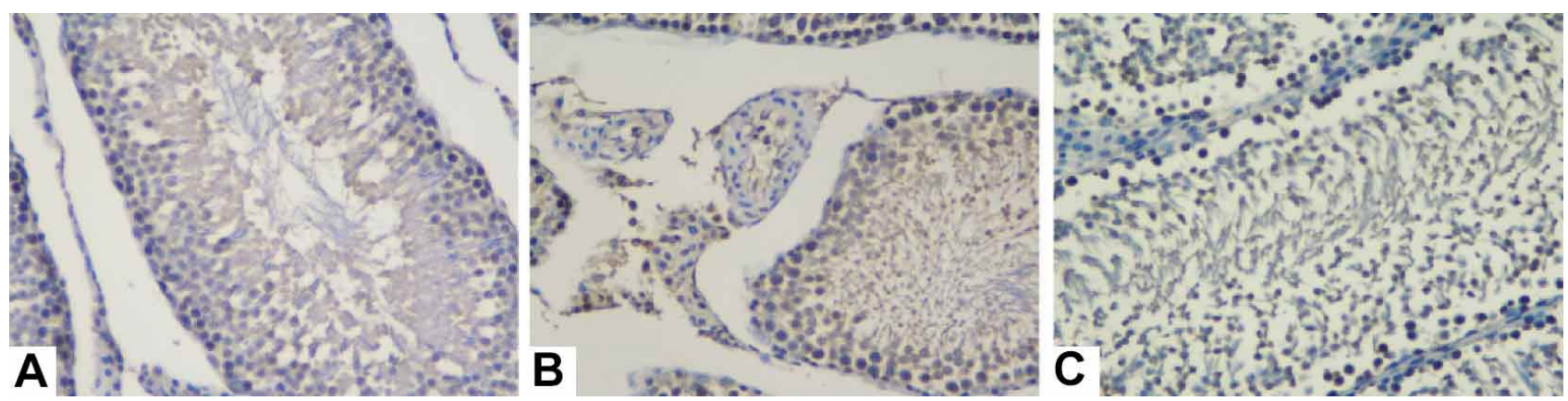

Fig. 4. This is seen after amplifying the results of immunohistochemistry. A is a blank control group. The nucleus of the spermatogenic cells of each layer was clearly visible, and the sperm cells in the seminiferous tubules were partially stained blue, and no brownish-yellow region was observed. B is a model group. In the seminiferous tubules, the primary spermatocytes, which are partially close to the basement membrane, show cytoplasm looming brownish yellow. Outside the seminiferous tubules, it can be clearly seen that the cytoplasm of some mesenchymal cells is stained brownish yellow. C crepe flavonoid group. Even after zooming in, no brown areas were found. $\mathrm{H} \& \mathrm{E} \times 400$.

\section{DISCUSSION}

Male fertility has been declining year by year, and oligospermia has received widespread attention. As an antitumor drug and immunosuppressive agent, cyclophosphamide is often used together with other chemotherapeutic drugs to treat various cancers and chronic autoimmune diseases. It mainly affects cell growth by crosslinking DNA strands to affect cell mitosis and cell differentiation. Because of this, cyclophosphamide has certain toxic side effects, especially those that are rapidly dividing cells in the reproductive system.

Cyclophosphamide has a significant effect on the reproductive system of male SD rats, resulting in a significant change in the testicular tissue structure, a decrease in sperm count and a decrease in viability, which seriously affects the reproductive function of rats. In this experiment, cyclophosphamide was used to establish a rat model of oligozoospermia (Hu et al., 2002; Wang \& Liang, 2006; Qi et al., 2010).

Cuscuta is a commonly used drug in the treatment of kidney deficiency, and flavonoids are the important components. In this experiment, compared with the model group, the sperm count and activity rate of the flavonoids in the Cuscuta chinensis group were significantly improved, the spermatogenic epithelium and basement membrane were intact, the number of spermatogenic cells and interstitial cells, and the number of sperm cells and sperm in the lumen increased significantly. The above results can confirm that the flavonoids of Cuscuta chinensis have a reproductive function protective effect on rats with oligospermia caused by cyclophosphamide. 
GM-CSF is widely expressed in the blood system and immune system. As one of the most common growth factors in the blood system, it promotes the maturation and differentiation of blood cells and enhances the immune function of the inflammation site. When GM-CSF acts on vascular endothelial cells and keratinocytes, it can promote its proliferation and migration, which is beneficial to angiogenesis and wound healing (Fang et al., 2017). GM-CSF is mainly derived from activated T cells, B cells, endothelial cells, macrophages, and fibroblasts, and is also expressed in neutrophils, epithelial cells, and some tumor cells. The high expression of GM-CSF in tumors is closely related to its ability to promote cell proliferation. In this experiment, spermatogenesis in the model group was blocked and GMCSF expression was enhanced. In the seminal plasma of patients with oligozoospermia, the content of GM-CSF is also higher than that of the normal group. Therefore, we believe that the testicular tissue is affected by the toxic effects of cyclophosphamide, and the expression of a series of cytokines such as GM-CSF increases, playing an important role. Cuscuta flavonoids may play a posotive role in the recovery of oligozoospermia by changing the expression of GM-CSF.

The results of immunization showed that the expression level of GM-CSF in the model group was much higher than that in the other two groups. It is indicated that when cyclophosphamide affects the spermatogenic function of testicular tissue, the internal environment of the body also produces a certain response, and efforts are made to coordinate the effects of different cytokines. We envisage that the highly expressed GM-CSF swims out of the testicular capillaries, enters the seminiferous tubules through the basement membrane of the seminiferous tubule rupture, acts on the spermatogenic cells and supporting cells, exerts antiinflammatory and promotes cell proliferation, thereby improving the large The spermatogenic function of the mouse. At the same time, the GM-CSF content in the flavonoids group of the Cuscuta chinensis was not different from that in the blank group, indicating that the high expression of GM-CSF may be improved after the improvement of the oligozoospermia or even recovery.

In summary, the flavonoids of Cuscuta chinensis have obvious protective effects on the spermatogenic function of rats with oligospermia caused by cyclophosphamide. The expression of GM-CSF in testis tissue of rats with oligozoospermia was significantly enhanced. High expression of GM-CSF disappeared after the use of dodder flavonoids to improve oligospermia. The detection of GMCSF expression in rats with oligozoospermia will help to further study the changes of cytokine expression in testis tissue under azoospermia, thus providing new ideas for clinical diagnosis and treatment of oligozoospermia.
XIAOTONG, M.; LIBIN, L.; YIXUAN, M.; KADIER, A. \& SHENGBIN, B. Identificación inmunohistoquímica de GM-CSF en testículos de ratas con oligozoospermia con la intervención de flavonoides de Cuscuta chinensis. Int. J. Morphol., 38(3): 761-765, 2020.

RESUMEN: La oligozoospermia es una enfermedad común de infertilidad, con una tasa de incidencia que aumenta año tras año. Cuscuta chinensis es un medicamento de uso común para el tratamiento de la oligozoospermia en la medicina china. Los flavonoides son su componente principal. GM-CSF es una citocina multifuncional que tiene un rol importante en la respuesta inflamatoria. En este trabajo, realizamos tinción con hematoxilina y eosina y tinción inmunohistoquímica en testículos de ratas con oligozoospermia. TNuestro objetivo fue estudiar los cambios de expresión de GM-CSF en ratas con oligozoospermia y el efecto de los flavonoides en la expresión de GM-CSF en testículos de ratas con oligozoospermia.

PALABRAS CLAVE: Flavonoides; Cuscuta chinensis; Oligozoospermia; GM-CSF.

\section{REFERENCES}

Fang, Y.; Cheng, R.; Wang, Y.; Xu, Y. \& Bao, S. Expression of inflammatory cells and GM-CSF during wound healing in diabetic mice. J. Shanghai Jiaotong Univ. (Sci.), (2):174-7, 2017.

Ghobadi, E.; Moloudizargari, M.; Asghari, M. H. \& Abdollahi, M. The mechanisms of cyclophosphamide-induced testicular toxicity and the protective agents. Expert Opin. Drug Metab. Toxicol., 13(5):525-36, 2017.

Hu, W.; Liu, Z.; Chen, H.; Tang, Z.; Wang, Q.; Shen, K. \& Li, L. Mycophenolate mofetil vs cyclophosphamide therapy for patients with diffuse proliferative lupus nephritis. Chin. Med. J. (Engl.), 115(5):705-9, 2002.

Lin, Y. \& Wu, J. Immunomodulatory effects of GM-CSF/IL-3/IL-5. Chin. J. Immunol., 35(04):122-6, 2019.

Potnuri, A. G.; Allakonda, L. \& Lahkar, M. Crocin attenuates cyclophosphamide induced testicular toxicity by preserving glutathione redox system. Biomed. Pharmacother, 101:174-80, 2018.

Qi, L.; Song, Y.; Wang, W.; Cui, W.; Zhang, X.; Liu, Z.; Sun, N. \& Li, N. Comparison of immunosuppression induced by different doses of cyclophosphamide in normal mice. Wei Sheng Yan Jiu, 39(3):313-5, 325, 2010.

Shabanian, S.; Farahbod, F.; Rafieian, M.; Ganji, F. \& Adib, A. The effects of Vitamin $\mathrm{C}$ on sperm quality parameters in laboratory rats following long-term exposure to cyclophosphamide. J. Adv. Pharm. Technol. Res., 8(2):73-9, 2017.

Sun, X. H.; Wang, L.; Sun, L. B.; Zhu, L. \& Affiliated Hospital of Medical College Qingdao University. Effect of Cuyu Shengjing granules on cyclophosphamide(CP)-induced asthenospermia and oligozoospermia in model rats. Chin. J. Hosp. Pharm, (20):1163-7, 2013.

Wang, X. Y. \& Liang, Q. J. Recent progress in research on toxicological mechanism of cyclophosphamide and the improving measures. Prog. Pharm. Sci., (10):4526, 2006 .

Zeng, G.; Wu, L.; Qiao, Z.; Li, Q.; Liu, X.; Zhou, N.; Pan, R.; Shi, Y.; Li, L.; Xu, Y.; et al. Effect of Baji oral solution on spermatogenesis effect and sperm motility in cyclophosphamide-induced oligospermia and asthenospermia model mice. China Pharm., (19):2631-5, 2018.

Zhang, J. The clinically experimental investigation on measuring EGF, GM-CSF, NPY and ET.1 in human seminal plasma. J. Shangdong Med. Coll., (1):11-5, 2008.

\section{Corresponding author: \\ Bai Shengbin \\ Department of Histology and Embryology \\ Xinjiang Medical University \\ Xinyi Road 393 Urumqi \\ Xinjiang - CHINA}

Email: bsbxx@126.com 